\title{
Testicular mass: a rare presentation of Richter's syndrome
}

\author{
Elsayed Desouky ${ }^{1 *} \mathbb{D}$, Wassim Al-Salti ${ }^{2}$ and Muhammad Khan ${ }^{1}$
}

\begin{abstract}
Background: Richter's syndrome is the transformation of indolent lymphoma into an aggressive form, most commonly diffuse large B cell lymphoma. Most patients are known to have chronic lymphocytic leukemia. Richter's syndrome arises in the lymph nodes or bone marrow and rarely presents with extra nodal involvement.

Case presentation: Our patient presented with Richter's syndrome at an extremely uncommon site, i.e., testis. This is the fourth case reported in literature. Moreover, our case represents the longest follow-up reported so far with recurrence-free survival of more than 2 years now.

Conclusion: Testicular mass in a patient with a history of chronic lymphocytic leukemia should raise the clinical suspicion of Richter's syndrome and accordingly the patient should be thoroughly investigated and treated. Treatment needs multidisciplinary team approach: urologist, pathologist and hematologist.
\end{abstract}

Keywords: Richter's syndrome, Lymphoma, Testicular mass, Orchidectomy, Case report

\section{Background}

Testicular lymphoma is an uncommon testicular neoplasm representing $5 \%$ of all testicular malignancies. Nevertheless, testicular lymphoma is the most common testicular tumor in men over the age of 60 and it is the most common bilateral testicular neoplasm: synchronous at presentation in $6-10 \%$ of cases [1]. Lymphoma of the testes may be primary; starting in the testes, or it may involve the testes as part of a widespread disease that involves many other organs as in non-Hodgkin lymphomas (NHLs). Testicular lymphoma represents only $1-2 \%$ of all NHLs. However, diagnosis of testicular lymphoma as secondary - a part of NHLs is more common than primary extranodal disease. The commonest presentation of testicular lymphoma is a painless unilateral testicular mass or swelling. Following inguinal orchiectomy, diffuse large $B$ cell lymphoma (DLBCL) is the most frequent histopathological diagnosis [1].

\footnotetext{
*Correspondence: sayedurology@hotmail.com

${ }^{1}$ Department of Urology, Wexham Park NHS Hospital, Berkshire SL2 4HL, UK

Full list of author information is available at the end of the article
}

On the other hand, Richter syndrome (RS) represents the transformation of chronic lymphocytic leukemia (CLL) to an aggressive form of lymphoma. RS is mostly represented by diffuse large B cell lymphoma (DLBCL). RS is clinically characterized by development of B symptoms (fever, night sweats and weight loss), rapid clinical deterioration and a rapid increase in the size of lymphadenopathy and /or splenomegaly [2]. Majority of patients with RS are known cases of CLL. Richter's syndrome commonly arises in lymph nodes or bone marrow and disseminates to other organs. Rarely, it may present at extra nodal sites, e.g., gastrointestinal, pulmonary, pharyngeal, osseous, dermatologic or neurologic system involvement. Involvement of the testicle, as in this case, is quiet rare and there are only few cases reported in the literature [2].

\section{Case presentation}

This is a case report of a 72-year-old male patient who presented to his General Practitioner (GP) with a painless right sided scrotal swelling for few weeks.

The patient had a history of G2Ta transitional cell carcinoma (TCC) of the bladder since 2016 and was on 
regular surveillance with cystoscopy and Mitomycin-C (MMC) intravesical treatment. The patient had a history of stage A CLL since 2015 and was under surveillance by hematology team.

After examining the patient, the GP requested a Doppler ultrasound (Philips Epiq $7^{\circledR}$ ) (US) scan testes which showed that right testis appeared diffusely enlarged and diffusely hypoechoic with marked hyper vascularity, no calcification and no obvious discrete masses. The report suggested the diagnosis of epididymo-orchitis (Fig. 1). The GP started the patient on a course of an antibiotic (Ciprofloxacin) but given the concern about the 'painless' testicular mass, GP decided to refer the patient for urology consultation.

In January 2019, the patient attended in our urology outpatient clinic. Scrotal examination revealed about 10 $\mathrm{X} 10 \mathrm{~cm}$ hard non-tender right-sided scrotal mass with normal left testicle. There was no peripheral lymphadenopathy or organomegaly.

Peripheral blood counts showed WBC $=17.5 \times 10^{9} / \mathrm{L}$ with neutrophils of $4.39 \times 10^{9} / \mathrm{L}$, lymphocytes of $11.16 \times 10^{9} / \mathrm{L}$. Testicular tumor marker; B-HCG $<1 \mathrm{IU} / \mathrm{L}$, $\mathrm{AFP}=2.3 \mathrm{IU} / \mathrm{ml}$ and $\mathrm{LDH}=169 \mathrm{IU} / \mathrm{L}$. Computed tomography (Siemens Healthcare ${ }^{\circledR}$ ) (CT) scan chest, abdomen and pelvis (CAP) reported some borderline enlarged left para-aortic and aorto-caval lymph nodes and Unremarkable abdominal viscera (Fig. 2).

Right inguinal orchidectomy was performed. Histopathology reported the entire right testicle was heavily infilterated with sheets of medium-sized and large lymphoid

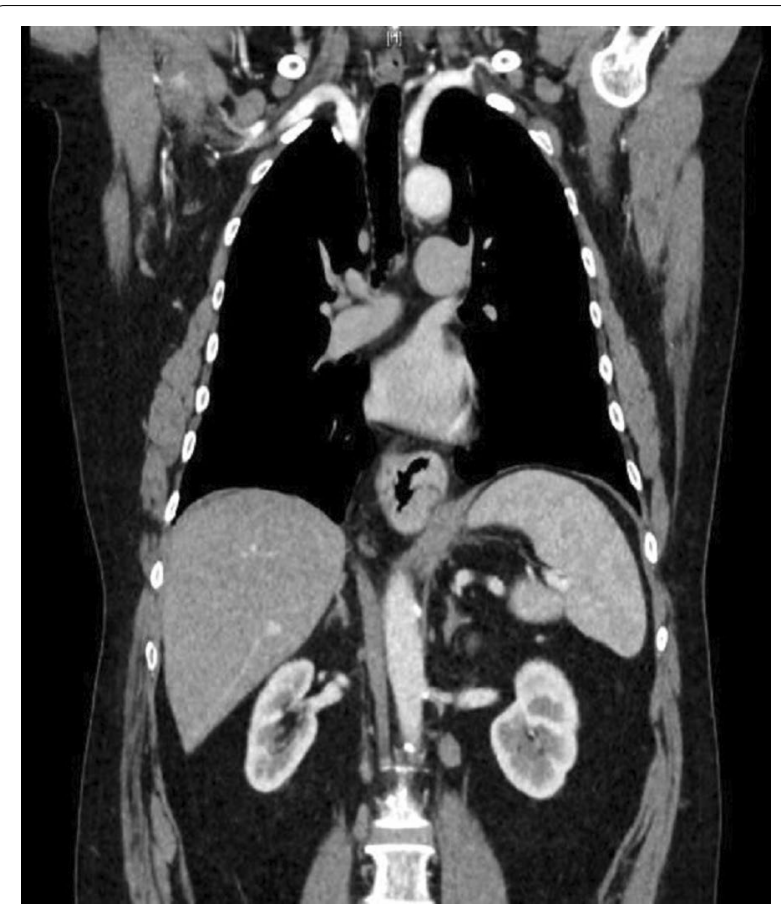

Fig. 2 CT CAP showing no significant lymphadenopathy

tissue associated with frequent mitotic figures. The infilteration was diffuse with no obvious nodular architecture. The atypical lymphoid cells were positive for CD20, CD79a, BCL-2, BCL-6, CD10 and MUM 1. There was negative staining for $\mathrm{CD} 23, \mathrm{CD} 5$ but showed weak

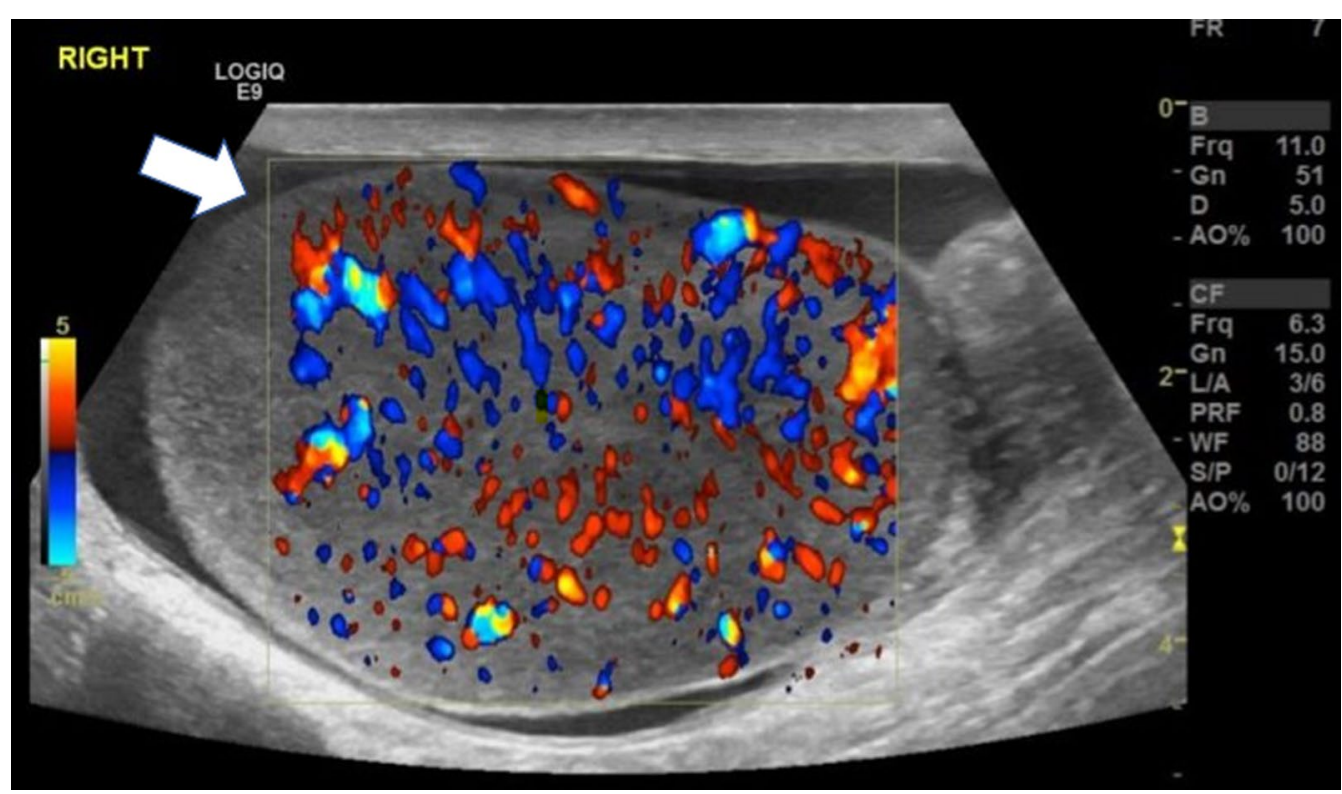

Fig. 1 USS right testicle showing diffuse enlargement with hypervascularity 


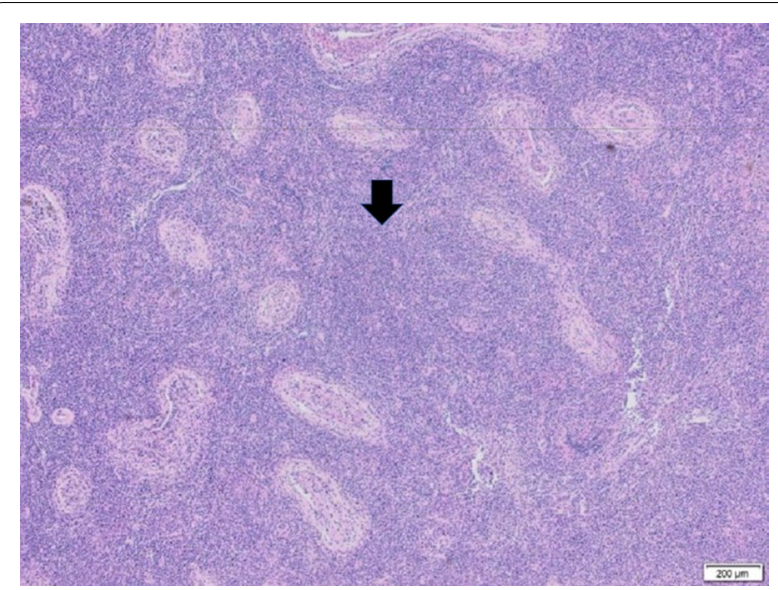

Fig. 3 Diffuse infiltration of right testicular tissue with lymphoid tissue with no obvious nodular architecture

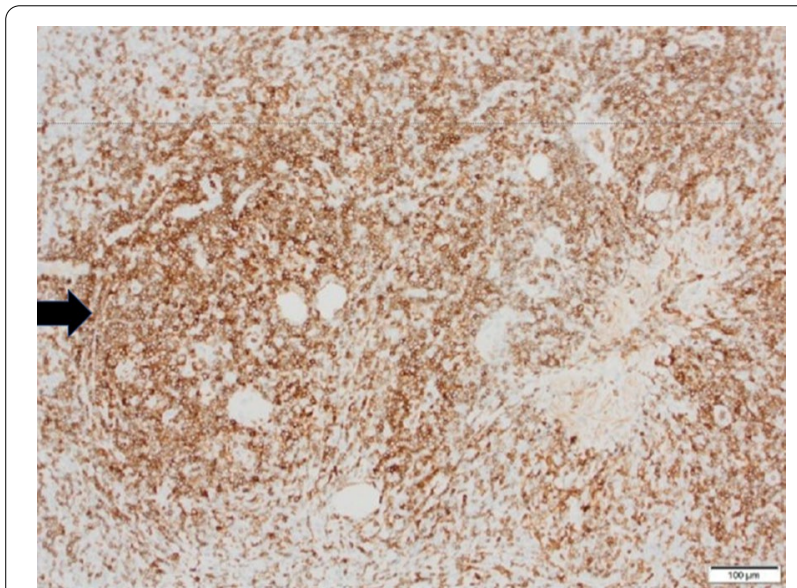

Fig. 4 Immuno-histochemical staining negative for CD 5

wide spread Lef-1 nuclear staining. The morphology and immunohistochemistry profile were consistent with a high grade Richter's transformation to diffuse large B cell lymphoma of germinal center type, which was confirmed by expert second opinion (Figs. 3, 4, 5).

Two weeks postoperatively the patient presented with a right-sided scrotal swelling for which USS testes showed an approximately $76 \times 60 \times 57 \mathrm{~mm}$ avascular, right-sided well-defined cystic structure with internal debris and septations was identified; possibly a collection (Fig. 6). Surgical drainage of $200 \mathrm{ml}$ serosanguinous fluid was performed through a midline scrotal incision.

In view of development of RS, Hematology team planned the following treatment for the patient; first, to start on R-CHOP (Rituximab, cyclophosphamide, doxorubicin, vincristine and prednisolone).

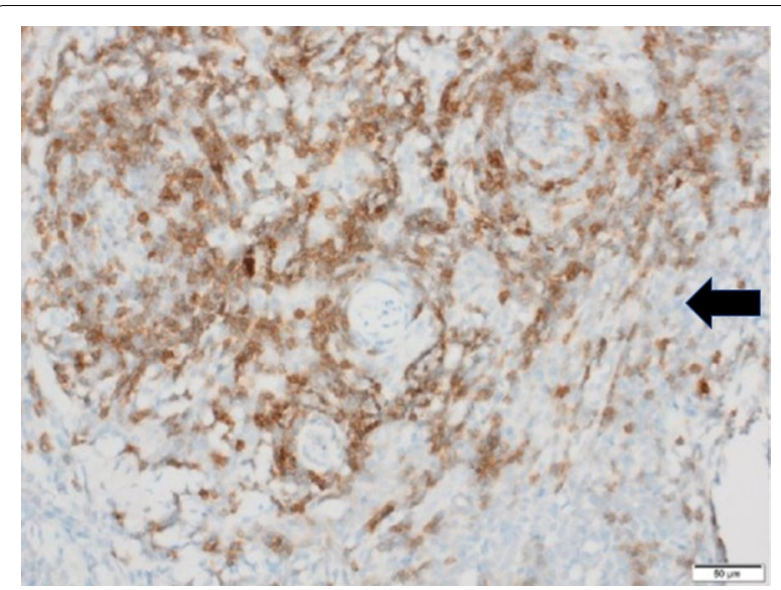

Fig. 5 Immuno-histochemical staining negative for CD 23

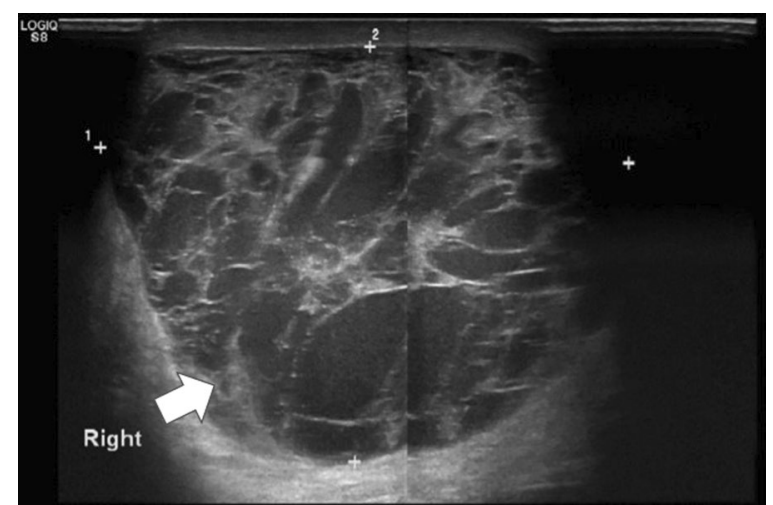

Fig. 6 USS testes 2 weeks postoperative showing right-sided scrotal collection

Secondly, as testicular lymphomas are associated with late lymphoma relapses around the brain or spinal cord; therefore, in order to reduce this risk, we proposed to give him methotrexate intrathecal (as a lumbar puncture) and two methotrexate treatments intravenously.

Finally, as testicular lymphomas tend to spread to the other testicle, the hematologist also recommended that the patient should consider either surveillance, radiotherapy or the last option to be removal of the other testicle (a contralateral orchiectomy).

After full counseling, our patient opted to go for contralateral orchiectomy after completing the whole course of chemotherapy as he was not accepting any possibility of recurrence; however, minimal that risk is. Simple orchidectomy was done and histopathology confirmed normal testicle. Our patient has been referred for endocrinology follow-up to manage his 
Table 1 Case reports of Richter's syndrome presenting as testicular mass

\begin{tabular}{|c|c|c|c|c|c|c|c|c|c|}
\hline Author & Year & Age (years) & CLL & $\begin{array}{l}\text { B } \\
\text { symptoms }\end{array}$ & $\begin{array}{l}\text { Testicular } \\
\text { mass }\end{array}$ & $\begin{array}{l}\text { WBC } \\
\text { count } \\
\left(\times 10^{9} / L\right)\end{array}$ & $C T$ & Treatment & $\begin{array}{l}\text { Recurrence } \\
\text { free } \\
\text { (follow-up) }\end{array}$ \\
\hline $\begin{array}{l}\text { Houdelette } \\
\text { et al. [9] }\end{array}$ & 1989 & $\mathrm{n} / \mathrm{a}$ & $\begin{array}{l}\text { Previously } \\
\text { diagnosed }\end{array}$ & Present & Unilateral & $\mathrm{n} / \mathrm{a}$ & $\mathrm{n} / \mathrm{a}$ & $\mathrm{n} / \mathrm{a}$ & $\mathrm{n} / \mathrm{a}$ \\
\hline Jha et al. [2] & 2014 & 52 & $\begin{array}{l}1^{\text {st }} \text { presenta- } \\
\text { tion (de } \\
\text { novo RS) }\end{array}$ & Present & Unilateral & 38 & $\begin{array}{l}\text { Retroperito- } \\
\text { neal mass }\end{array}$ & Orchidectomy + R-CHOP & 10 months \\
\hline $\begin{array}{l}\text { Kengo et al. } \\
\text { [8] }\end{array}$ & 2019 & 72 & $\begin{array}{l}\text { Previously } \\
\text { diagnosed }\end{array}$ & Absent & Bilateral & 27 & $\begin{array}{l}\text { Retroperito- } \\
\text { neal mass }\end{array}$ & $\begin{array}{l}\text { Bilateral Orchidec- } \\
\text { tomy + R-CHOP + Intrath- } \\
\text { ecal chemo }\end{array}$ & 12 months \\
\hline $\begin{array}{l}\text { ( present } \\
\text { case) }\end{array}$ & 2021 & 72 & $\begin{array}{l}\text { Previously } \\
\text { diagnosed }\end{array}$ & Absent & Unilateral & 17.5 & Negative & $\begin{array}{l}\text { Bilateral Orchidec- } \\
\text { tomy + R-CHOP + Intrath- } \\
\text { ecal chemo }\end{array}$ & 30 months \\
\hline
\end{tabular}

testosterone level. At almost two years follow-up, the patient is in remission.

\section{Discussion}

Testicular mass in a patient with a history of chronic lymphocytic leukemia should raise the clinical suspicion of Richter's syndrome and accordingly the patient should be thoroughly investigated and treated. Treatment needs multidisciplinary team approach: urologist, pathologist and hematologist.

The transformation of CLL into a clinico-pathologically more aggressive form is known as Richter's syndrome. This was originally described in 1928 by Maurice Richter [3]. Most patients have already been diagnosed with CLL. Such transformation occurs in up to $10 \%$ of all CLL patients usually within 1-4 years of diagnosis [3].

Clinically, Richter's syndrome is characterized by rapid growth of lymphadenopathy and the onset of B symptoms; defined as a recurrent fever of $>38^{\circ} \mathrm{C}$, night sweats, and weight loss $>10 \%$ within 6 months before diagnosis. Extra nodal disease can be seen and may involve the gut, central nervous system, lungs, kidneys and skin [4]. No laboratory findings are specific for RS [3]. Our patient presented with no B symptoms, normal LDH and no cytopenia.

On ultrasound scan examination, features for testicular lymphoma have been described as either nodular-type or diffuse-type. In the nodular type, the testicle is normal or slightly enlarged in size with hypoechoic nodules in the testicular parenchyma showing clear outline and regular morphology. In the diffuse-type, there is obvious testicular enlargement with diffuse hypoechoic involvement of almost the entire testicular parenchyma [5]. Our case showed the diffuse-type sonographic features.

Diagnosis of RS needs histopathological confirmation, e.g., lymph node biopsy as it is the most commonly involved site [4] or in our case the specimen following inguinal orchidectomy. Good communication with the histo-pathologist was of paramount importance in this case. It was essential to share all the relevant data including patient history, i.e., CLL, as well as the clinical suspicion about this testicular mass representing an uncommon pathological entity. Hence, further meticulous histo-pathological examination of the specimen with special immune-histochemical staining was performed together with an expert second opinion to confirm the final diagnosis.

Staging of lymphoma as adapted from Ann Arbor criteria for clinical staging of lymphoma include the following [6]:

StageI: Single lymphatic organ or single extra-lymphatic site.

StageII: Lymph node involvement on the one side of diaphragm.

Stage III: Lymph node involvement on both sides of diaphragm.

Stage IV: Non-contagious involvement of one or more extra-lymphatic site with or without lymph node involvement

Accordingly, our case fulfills the criteria of stage IV lymphoma.

Even following inguinal orchiectomy and R-CHOP chemotherapy, the most significant challenge in patient with testicular lymphoma is the potential for distant relapses at extra nodal sites particularly CNS and the contralateral testis. Radiotherapy to the contralateral testis can reduce this risk [7]. Hence, the hematologist advised our patient to have the intrathecal methotrexate prophylaxis to the CNS. Moreover, our patient was given the option of testicular radiotherapy yet he opted to go for contralateral orchiectomy. The patient was later 
referred to endocrinology team for follow-up with regard to possible testosterone replacement therapy.

Searching the published literature, we found only three similar case reports (Table 1). Our case is the fourth case report in the published literature as Richter's transformation of CLL presenting as a testicular mass, which is a rare extra nodal site for Richter's syndrome. Interestingly, our case presented exclusively with unilateral testicular mass with neither B symptoms nor any other clinical or radiological evidence of RS. Moreover, this case represents the longest follow-up reported so far with a recurrence free survival of over 2 years now $[2,8,9]$.

\section{Conclusion}

Management of this patient needed multidisciplinary team approach; a urologist to operate, a pathologist to examine the specimen and a hematologist to give a follow-up plan. Our patient had an inguinal orchidectomy for a hard right testicular mass. Histopathological examination confirmed Richter's syndrome for which the hematologist decided to start him on R-CHOP regimen, methotrexate to protect the CNS and patient opted to go for contralateral orchidectomy rather than radiotherapy to guard against testicular relapse. Almost two years follow-up now, our patient is in remission.

\section{Abbreviations \\ NHL: Non-Hodgkin Lymphoma; DLBCL: Diffuse Large B Cell Lymphoma; RS: Richter's syndrome; CLL: Chronic Lymphocytic Leukemia; GP: General Practi- tioner; LDH: Lactate Dehydrogenase.}

\section{Authors' contributions}

ED wrote the first draft of the manuscript. WS reviewed the pathology section in the manuscript as well as the comment on the histopathology slide photos. MJK reviewed the overall scientific content and comments on the imaging scan photos. All authors reviewed and edited the manuscript and approved the final version of the manuscript.

\section{Declarations}

Ethics approval and consent to participate

Our institution does not require ethical approval for reporting individual cases or case series.

\section{Consent for Publication}

Written informed consent was obtained from the patient for anonymized information to be published in this article.

\section{Competing interests \\ Nothing to declare.}

\section{Author details}

${ }^{1}$ Department of Urology, Wexham Park NHS Hospital, Berkshire SL2 4HL, UK.

${ }^{2}$ Department of Pathology, Wexham Park Hospital, Berkshire, UK.

Received: 9 December 2020 Accepted: 13 September 2021

Published online: 28 September 2021

\section{References}

1. Andrea GL, Nicholas P, Brian H, Rekha G (2009) Malignant lymphoma of the testis: a study of 12 cases. CUJA 3(5)

2. Bhawna J, Jasmita D, Ritesh S, Rahul B (2014) Testicular swelling: A rare manifestation of chronic lymphocytic leukemia presenting with Richter's syndrome. Indian J Pathol Microbiol 57:133-135

3. Pula B, Salomon A, Prochorec-Sobieszek M, Jamroziak K (2019) Immunotherapy for Richter syndrome: current insights. Immunotargets Ther 8:1-14

4. John NA, Richard RF (2018) Current trends in the management of Richter's syndrome. Int J Haematol Oncol 7(4): IJHO9

5. Wang Q, Zheng D, Chai D, Wu S, Wang X, Chen S, Wu L, Cao R, Tao Y (2020) Primary testicular diffuse large B-cell lymphoma: case series. Medicine (Baltimore) 99(12):e19463

6. Chen B, Cao DH, Lai L, Guo JB et al (2020) Adult primary testicular lymphoma: clinical features and survival in a series of patients treated at a high-volume institution in China. BMC Cancer 20(1):220

7. Vitolo U, Chiappella A, Ferreri AJ, Martelli M et al (2011) First-line treatment for primary testicular diffuse large B-cell lymphoma with rituximabCHOP, CNS prophylaxis, and contralateral testis irradiation: final results of an international phase II trial. J Clin Oncol 29(20):2766-2772

8. Kengo K, Taku N, Aya N, Masamitsu Y, Youske I, Yuya O et al (2019) Rare case of Richter syndrome with testicular involvement successfully obtained good prognosis with rapid operation and immunochemotherapy. IJU Case Reports 2:232-235

9. Houdelette P, Dumotier J, Hauteville D, Pierre C, Berthod N (1989) Richter's syndrome with testicular localization. J Urol (Paris) 95:507-508

\section{Publisher's Note}

Springer Nature remains neutral with regard to jurisdictional claims in published maps and institutional affiliations.

\section{Submit your manuscript to a SpringerOpen ${ }^{\circ}$ journal and benefit from:}

- Convenient online submission

- Rigorous peer review

- Open access: articles freely available online

- High visibility within the field

- Retaining the copyright to your article

Submit your next manuscript at $\boldsymbol{\nabla}$ springeropen.com 